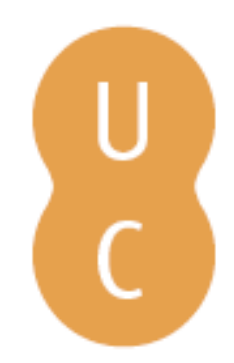

\title{
pompalina
}

\section{Entre a medicina e a filosofia: a apologia de comer vegetais em Plutarco}
Autor(es):
Pinheiro, Joaquim
Publicado por: Imprensa da Universidade de Coimbra; Annablume
URL
persistente:
URI:http://hdl.handle.net/10316.2/39645
DOI:
DOI:https://doi.org/10.14195/978-989-26-1191-4_16
Accessed : $\quad$ 26-Apr-2023 15:36:47

A navegação consulta e descarregamento dos títulos inseridos nas Bibliotecas Digitais UC Digitalis, UC Pombalina e UC Impactum, pressupõem a aceitação plena e sem reservas dos Termos e Condições de Uso destas Bibliotecas Digitais, disponíveis em https://digitalis.uc.pt/pt-pt/termos.

Conforme exposto nos referidos Termos e Condições de Uso, o descarregamento de títulos de acesso restrito requer uma licença válida de autorização devendo o utilizador aceder ao(s) documento(s) a partir de um endereço de IP da instituição detentora da supramencionada licença.

Ao utilizador é apenas permitido o descarregamento para uso pessoal, pelo que o emprego do(s) título(s) descarregado(s) para outro fim, designadamente comercial, carece de autorização do respetivo autor ou editor da obra.

Na medida em que todas as obras da UC Digitalis se encontram protegidas pelo Código do Direito de Autor e Direitos Conexos e demais legislação aplicável, toda a cópia, parcial ou total, deste documento, nos casos em que é legalmente admitida, deverá conter ou fazer-se acompanhar por este aviso.

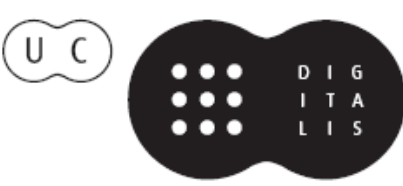




\title{
Entre a medicina e a filosofia: A APOLOGia de comer vegetais em Plutarco Between medicine and philosophy: the apology of eating vegetables in Plutarch
}

\author{
Joaquim Pinheiro \\ Universidade da Madeira \\ Centro de Estudos Clássicos e Humanísticos (Universidade de Coimbra) \\ joaquim.pinheiro@staff.uma.pt
}

Resumo: Tendo em conta os tratados Preceitos para conservar a saúde (De tuenda sanitate praecepta), Da inteligência dos animais (De sollertia animalium) e, em particular, Sobre comer carne (De esu carnium), procuraremos identificar os principais elementos da concepção plutarquiana sobre a diaita. Embora Plutarco manifeste conhecimentos e interesse pela medicina (Tsekourakis 1987, Boulogne 1996), a saúde e a diaita ou mesmo a alimentação, estando ao serviço da mensagem ético-pedagógica, surgem como requisitos essenciais para a vida harmoniosa do homem, na sua relação com a natureza e os outros seres vivos.

Palavras-chave: Plutarco, saúde, diaita, De esu carnium, animais, vegetais.

Aвstract: Considering Plutarch's treatises De tuenda sanitate praecepta, De animalium sollertia and especially De esu carnium, this analysis seeks to identify the main elements of Plutarch's conception of diaita. Although Plutarch has a solid knowledge and interest in medicine (Tsekourakis 1987, Boulogne 1996), health and diaita or even food, being at the service of his ethical and pedagogical message, emerge as essential requirements for the harmonious life of mankind in their relationship with nature and other living beings.

Keywords: Plutarch, health, diaita, De esu carnium, animals, vegetables.

Ouve-se com alguma frequência que a alimentação passou a ser uma preocupação do nosso tempo, como se fosse algo novo. No entanto, tal ideia não é correcta. Nos textos antigos da tradição greco-latina, em tratados médicos ou filosóficos, mas também na historiografia ou na comédia grega, encontram-se reflexões sobre o valor da alimentação para o Homem. Trata-se, por isso, de um tema que, em diferentes contextos e merecendo perspectivas de análise também elas diferenciadas, figurou desde há muito entre as preocupações das sociedades, sendo, por isso, um elemento civilizacional e cultural de extrema importância. Com base na selecção de alguns textos da obra de Plutarco, procuraremos analisar a concepção de diaita e a argumentação em favor da abstinência de carne, num contexto narrativo que oscila entre a tendência 
técnica ou médica e o conteúdo ético-moral. Diógenes Laércio (3. 85), ao

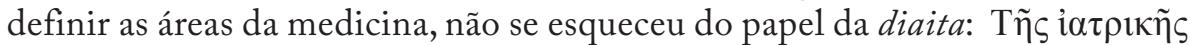

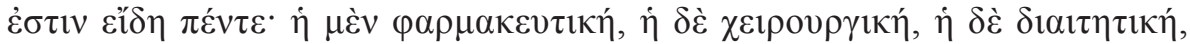

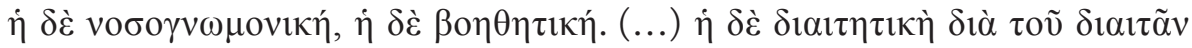

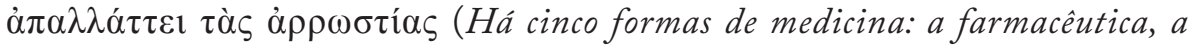
cirúrgica, a dietética, a diagnóstica e a de cuidados continuados. (...) A dietética afasta as enfermidades por meio da dieta). De facto, a noção de que a diaita é muito importante para evitar doenças surge repetida em muito textos médicos, mas, como veremos, a acção da diaita é mais ampla na vida do homem.

Sem querermos ser exaustivos e usando como fonte apenas Diógenes Laércio, sabemos que Aristóteles escreveu um tratado de anatomia, em oito livros, e um sobre medicina (5.22-27); Teofrasto, por sua vez, escreveu sobre a epilepsia e dedicou um outro tratado ao tema das pestes (5. 43-44); Estratão, que dirigiu o Liceu entre os anos 286 e 268 a. C., terá escrito os tratados Sobre

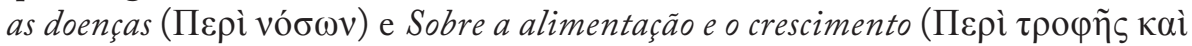
$\alpha \hat{\xi} \xi \eta \dot{\eta} \sigma \omega \varsigma$ ), este directamente relacionado com o tema da diaita (5.59). Se hoje a medicina e a filosofia pertencem a áreas distintas do conhecimento, na Antiguidade Clássica, pelos três exemplos indicados, a que podemos juntar o de Plutarco, a materia medica não é exclusiva dos médicos, mas também os filósofos, e não só, se dedicaram a ela. No próprio corpus hipocrático, em particular no tratado Da antiga medicina (De prisca medicina), reforça-se a relação entre medicina e filosofia, com alguma vantagem para esta: $\Lambda \dot{\gamma} \gamma 0 v \sigma \imath$

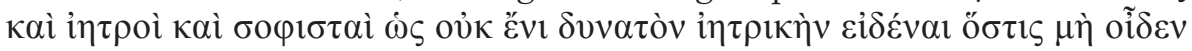

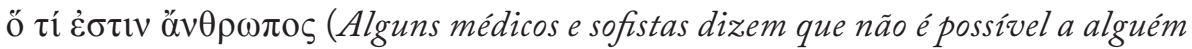
saber de medicina se não se souber quem é o homem) (20). Galeno' ${ }^{1}$, por sua vez, no tratado Que o melhor médico seja também um filósofo (Quod optimus medicus sit quoque philosophus), tendo por paradigma o médico hipocrático, amigo da verdade e conhecedor da natureza humana, afirma (1.61):

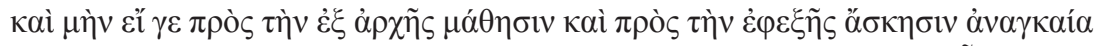

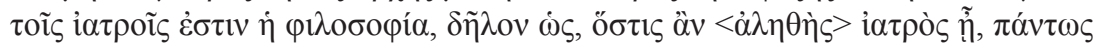

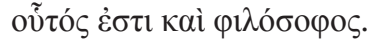

E certamente que se para aprendizagem inicial e para o exercício continuado a filosofia é fundamental para os médicos, evidentemente que aquele que for um <verdadeiro> médico será sem dúvida também filósofo² ${ }^{2}$.

${ }^{1}$ Cf. M. Vegetti 1994: 1672-1717.

2 Platão, nas Leis 720A, distingue os verdadeiros médicos dos 'servos' da medicina que exercem conhecimento da physis. Também Galeno, no tratado Que o melhor médico seja também um filósofo (Quod optimus medicus sit quoque philosophus) critica a formação dos médicos do seu tempo e por se tornarem escravos da riqueza, preferindo realçar o valor do trabalho, condição necessária para quem ambiciona ser médico, a par da moderação e da opção pela verdade. 
Nesta obra, Galeno estabelece um paralelo entre o médico e o filósofo, a partir das três disciplinas da filosofia helenística (Lógica, Física e Ética). Assim, no âmbito da medicina, a física estudaria os órgãos, a lógica faria o exame das doenças, indicando as suas características e tipologia, enquanto a ética, como forma de humanizar os médicos, os obrigaria a cuidar de todos os pacientes e a serem moderados. Para Galeno, o médico tem de saber equilibrar a prática com a teoria, daí que critique os médicos do seu tempo, não só porque se preocupam mais com a riqueza do que com a questão ética do exercício da sua profissão, mas também por venerarem Hipócrates, mas não lerem as suas obras, nem aplicarem os seus ensinamentos (1.55). E isso só está ao alcance de um médico pepaideumenos, isto é, um iatrosophistes ou iatrophilosophos com uma formação geral adequada e com valores morais.

Plutarco 3 , por sua vez, no tratado Sobre o amor à riqueza (De cupiditate diuitiarum), assemelha a acção do médico à do filósofo, uma vez que tal como o médico diz "doença mental" ao examinar um homem na cama, a contorcer-se com dores, que não quer comer, mas que não tem febre, também o filósofo faz igual diagnóstico ao homem vencido pela ganância (cf. 524D-E). Mas sobre a relação entre medicina e filosofia ${ }^{4}$, o melhor exemplo que a obra de Plutarco nos oferece é o início do tratado Preceitos para conservar a saúde (De tuenda sanitate praecepta $)^{5}$. Zeuxipo em diálogo com Mósquion conta-lhe que Glauco, um médico, os tinha repreendido por se terem aventurado a falar sobre

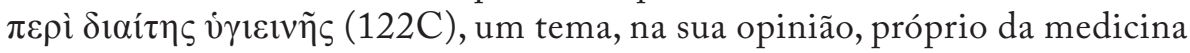
e não de filósofos. Ora, Mósquion, também ele médico, não concorda com Glauco, pelo respeito e interesse que tem pela filosofia. E, por isso, Zeuxipo explica-lhe (122D-E):

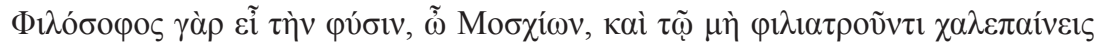

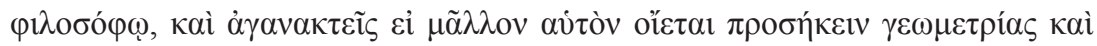

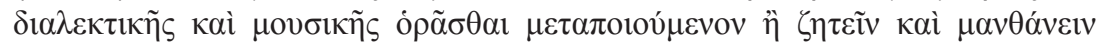

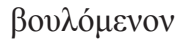

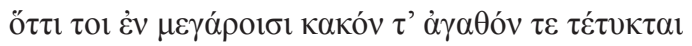

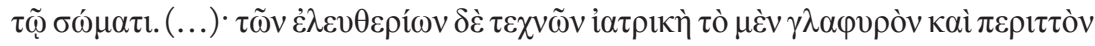

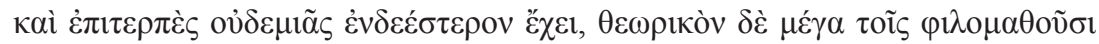

\footnotetext{
${ }^{3}$ Sobre o tema da medicina em Plutarco, vide D. Tsekourakis 1987 e J. Boulogne 1996.

${ }^{4}$ Nos Tratados Morais, Plutarco também estabelece uma relação entre a medicina, como arte que cura e mantém a saúde do corpo de um indivíduo, e a política, enquanto actividade que procura o bem-estar e que zela pela saúde de um conjunto de cidadãos. Veja-se, em particular, o tratado Conselhos Politicos (Praecepta gerendae reipublicae) 815A-C (conceito de 'medicina política').

${ }^{5}$ Também Galeno escreveu, em seis livros, um tratado intitulado De sanitate tuenda, assim como Célio Aureliano e Celso.
} 


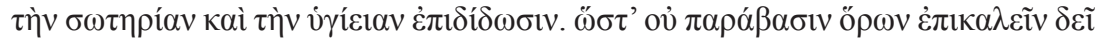

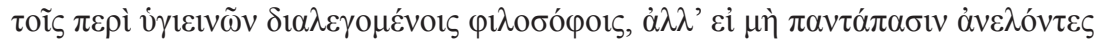

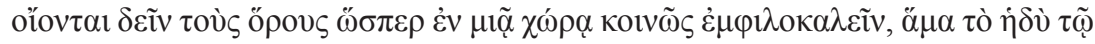

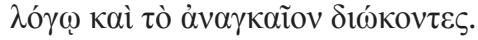

[Zeuxipo] Na verdade, Mósquion tu és filósofo por natureza e irritas-te com o filósofo que não ama a medicina e indignas-te se pensa que lhe convém mais que o vejam preocupar-se com a geometria, a dialéctica e a música do que desejando averiguar e aprender

o que sucede de mau e bom numa morada (cf. Od. 4. 392)

que é o corpo. (...) Entre as artes liberais, a medicina não é inferior a nenhuma em elegância, distinção, satisfação e concede aos seus estudiosos uma grande recompensa: o bem-estar e a saúde do corpo. Por conseguinte, não se deve acusar os filósofos de ultrapassar as fronteiras se discutem sobre temas de saúde, mas, antes pelo contrário, deveriam ser acusados se não pensam que é necessário, abolindo por completo as fronteiras, como se estivessem num só campo, dedicar-se a estes estudos em comum, buscando na discussão o agradável e o necessário.

É, por meio deste diálogo inicial, que Plutarco justifica a sua autoridade ao tratar da saúde, que não é uma temática exclusiva da área médica, mas que também deve contar com o valioso contributo dos filósofos. Na verdade, o tratado Preceitos para conservar a saúde não se caracteriza por uma abordagem médica ou técnica da saúde, mas, sobretudo, ética, atendendo a que se defende no tratado a ideia de que a saúde é uma condição sine qua non para a virtude (arete), na medida em que se valoriza o equilíbrio corpo-alma, um topos recorrente na filosofia antiga. Como provável marca da influência de Asclepíades da Bitínia, que exerceu medicina em Roma, este tratado faz a apologia da terapia por meio da diaita e não pelo uso de fármacos. Em resumo, por influência do médico hipocrático, a receita de Plutarco para

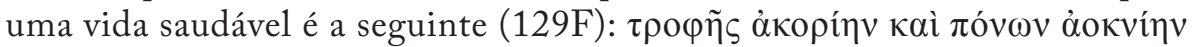

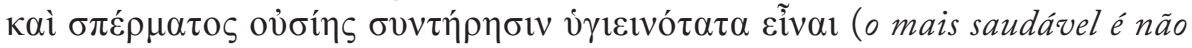
comer de forma insaciável, não trabalhar até à exaustão e procriar com cautelas).

$\mathrm{Na}$ linha encomiástica da vida saudável, considera-se que a falta de saúde impede, por exemplo a actividade política (politeia) (cf. 126B-C e 137D-E), pois a saúde não deve implicar inactividade (apraxia) (cf. 135B-C e 465C), da mesma maneira que, exemplifica Plutarco, não se conservam os olhos não olhando ou a voz sem falar. Logo, a saúde desempenha um papel social muito relevante. Cita mesmo o médico hipocrático para reforçar esta ideia e o proveito do exercício físico: A saúde não se compra com o ócio e a inactividade (135B; cf. Hip. Diaita 2.60). Deste modo, embora seja difícil educar o apetite (orexis), para Plutarco o homem deve saber definir aquilo que é proveitoso e viver segundo a necessidade, sem excessos. Quanto à comida, 
repete-se o princípio da moderação, ainda que, como Catão Censor terá

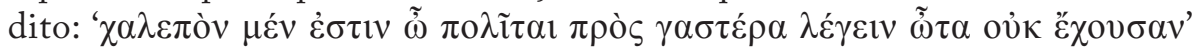
(Cidadãos, é difícil falar a estômagos que não têm orelhas) (Plut. Cat. Ma. 8.1). Plutarco enumera as comidas sólidas e as ligeiras para, de seguida, aconselhar

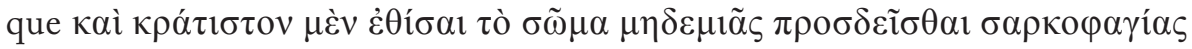
(o ideal é, em verdade, acostumar o corpo a de modo algum desejar comer carne) $(131 \mathrm{~F})$. Plutarco justifica esta afirmação de forma abreviada: por um lado, a terra produz sustento (diatrophe) em abundância para o homem, por outro, alimentar-se de carne é contra naturam, pois o homem não é como os lobos ou os leões, mas pode satisfazer-se com outros alimentos que estão mais de acordo com a natureza e que não debilitam a alma. No tratado Sobre comer carne, sustenta que com o consumo de carne o corpo fica entorpecido, pesado e repleto de alimentos impróprios $(995 \mathrm{~F})$ e isso tem consequências no próprio fulgor do espírito que se torna errante e débil, incapaz de examinar o objectivo das coisas. Com efeito, seguindo a teoria da metempsicose de Empédocles e dos Pitagóricos, Plutarco afirma que as almas ficam presas em corpos mortais como castigo pelos assassinatos, pelo consumo de carne animal e pelo canibalismo (cf. 996B-C), o que leva a uma perda de lucidez e à incapacidade de se dedicar à vida social. Pois, ficando os sentidos toldados e enfermos, as leis da natureza não são respeitadas. Daí que o acto de comer carne ultrapasse, na maioria das vezes, a simples relação entre o homem e o alimento, para dar lugar a uma pseudo-necessidade que resulta da gula, da falta de temperança ou mesmo do mero capricho; recorrendo a um símile, Plutarco explica que tal como a paixão amorosa arrasta (as mulheres) para acções nefastas, também a falta de sophrosyne ${ }^{6}$ na relação com a comida converte o apetite, natural e necessário, em paranomos (cf. 997B).

Ora, nos tratados De sollertia animalium ( $D$ a inteligência dos animais), Bruta animalia ratione uti (Os animais são racionais), mais conhecido por Gryllus (diálogo, na ilha de Circe, entre Ulisses e um porco de nome Grilo) e no De esu carnium (Sobre comer carne) ${ }^{7}$ estes argumentos repetem-se, ainda que a narrativa, nestes casos, se desenvolva sobretudo em torno de questões relacionadas com a natureza dos animais, colocando-se a possibilidade de existir virtude e razão entre os animais, ou de estes terem inteligência ${ }^{8}$. Para

${ }^{6}$ Cf. J. F. Montiel Martos 1996: 205-210.

${ }^{7}$ Seguimos a edição de L. Inglese \& G. Santese 1999.

${ }^{8}$ Galeno, no tratado Adhortatio ad artes addiscendas (Exortação à medicina) 1.1., define assim

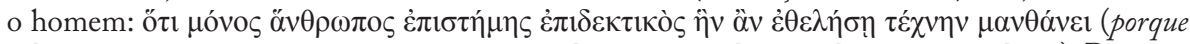
o homem é o único que, por estar apto para o conhecimento, pode aprender a arte que deseja). Por isso, o homem é capaz de aprender as artes dos animais (por exemplo, sabe tecer como as aranhas, modela como as abelhas e até nada, apesar de ser pedestre), as artes divinas (imita a arte médica de Asclépio e as artes de Apolo, como a música e a adivinhação, além das artes de cada uma das Musas). Além disso, conhece, por seu mérito, a geometria, a astronomia e a filosofia. Apesar 
Plutarco, todos os seres vivos merecem ser tratados com philanthropia e generosidade, opondo-se, assim, ao simples utilitarismo ou ao problemático princípio da necessidade de se sacrificarem animais com o fim de alimentar o homem. Nesse sentido, e em defesa da benevolência a ter com todos os seres, várias vezes se apela ao longo do tratado De esu carnium à piedade para com animais. Vejamos dois exemplos (994E e 996A):

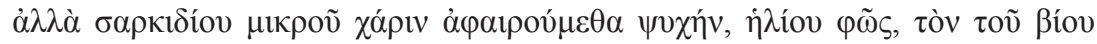

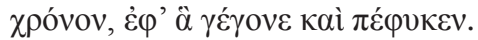

Mas, por causa de um pequeno pedaço de carne, privamos a alma [do animal] da luz do sol, do curso da vida, para as quais nasceu e foi gerada.

X

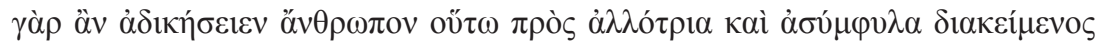

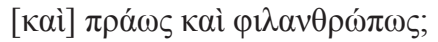

Fora isto, não parece que o costume da filantropia é algo admirável? De facto, quem poderia ser injusto com um homem que se relaciona com os de outra espécie de forma amável e filantrópica?

No primeiro texto citado, Plutarco parece ser influenciado pela escola de Teofrasto, atendendo à noção humana de psyche aplicada aos animais. Quanto ao segundo texto, transparece uma certa visão antropocêntrica (veja-se a referência a "os de outra espécie”), porventura de raiz pitagórica. Além disso, a noção de philanthropia é diferente da dos Estóicos, porque, tal como Teofrasto, considera que todos os seres vivos podem participar desse valor.

Em coerência com a valorização dos animais enunciada em outros tratados (e.g., possuem a faculdade de raciocinar, formulam pensamentos, têm alma, inteligência e capacidade sensitiva), no tratado De esu carnium, mais do que a apologia de comer vegetais ${ }^{9}$, Plutarco faz a apologia da abstinência da

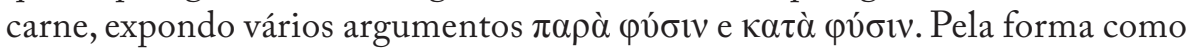
Plutarco desenvolve a sua argumentação em torno da abstinência da carne, tem havido a tendência de reduzir o referido tratado a um mero exercício retórico ou mesmo desvalorizá-lo por não nos ter chegado completo e por denotar alguma desorganização interna dos conteúdos. Porém, concordamos com aqueles que, além do valor retórico, também salientam o seu conteúdo zoopsicológico ${ }^{10}$ e a própria concepção de diaita ('regime geral de vida' ou

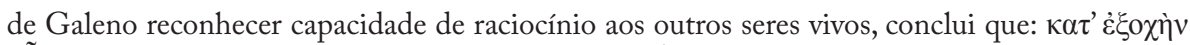

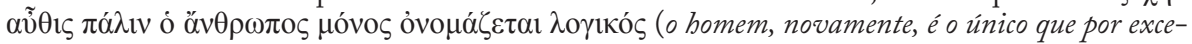
lência é chamado 'racional').

${ }^{9}$ Vide, em particular, o estudo de D. Tsekourakis 1987.

${ }^{10}$ Sobre esta temática na obra de Plutarco e do seu efeito retórico, vide Barigazzi 1992: 297-316, Becchi 1993: 59-83, 2001: 119-135, 2002: 159-174, 2005: 145-155, 2006: 205-225, J. 
'conduta'), um dos três elementos da medicina (cf. 974A), juntamente com a farmacopeia e a cirurgia.

Assim, não se distingue o tratado De esu carnium pelos seus apontamentos médicos ou técnicos, mas pelo valor filosófico, uma vez que reflecte o sincretismo que se produziu entre a filosofia pitagórica e a platónica, corrente a que se chamaria 'platonismo médio', nas épocas helenística e romana. Além disso, ao contrário dos filósofos do Pórtico, defensores de que os animais carecem da capacidade de raciocínio (logos), ainda que reconheçam que possam percepcionar (aisthesis), saibam representar (phantasia), tenham instinto (horme) e alma (psyche), Plutarco sustenta que, de forma natural, os animais apresentam algum grau de inteligência, facto que os aproxima dos seres humanos e, em consequência disso, deve-se, naturalmente, evitar o consumo de carne. A argumentação para demonstrar que a sarcofagia é anti-natura e não necessária, serve também para mostrar a oposição de Plutarco à visão excessivamente antropocêntrica dos Estóicos. Baseando-se em Xenócrates e Teofrasto, condena a brutalidade humana contra os animais quando privam esses seres da vida. ${ }^{11}$ Diógenes Laércio, a este propósito, conta a história de Xenófanes que mandou parar os maus tratos a um cão porque reconhecia nos latidos a voz de um amigo.

Para Plutarco, provavelmente por influência de Teofrasto, o homem começou a consumir carne por necessidade, como forma de vencer a penúria (aporia) ${ }^{12}$. Porfírio ${ }^{13}$ (De abst. 1.13), por sua vez, relaciona o início da sarcofagia com a descoberta do fogo, argumentando que está na natureza

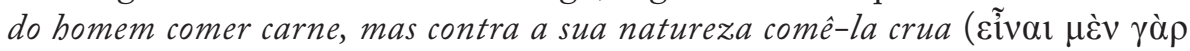

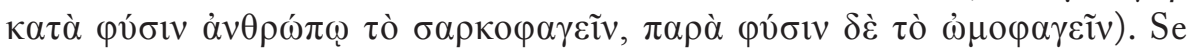
o acto de comer carne é paranomos, quando não se baseia numa verdadeira necessidade, qual é a vantagem de se comerem vegetais? Podem comer-se crus. Recorde-se que Pitágoras aconselha alimentos que não necessitem de fogo, para que os homens se pudessem habituar a uma alimentação frugal e simples. Também Epicuro não havia repudiado explicitamente o consumo de carne, mas recomendado uma alimentação com moderação.

Ainda relativamente ao conceito supostamente universal da 'necessidade', na teoria estóica, a verdade é que a melhoria das condições de vida acaba

Boulogne 2005, D’Ippolito 2000: 543-562, J. A. Fernández Delgado 2008: 23-32.

${ }^{11}$ Cf. 994F ss.: Refira-se, por exemplo, o seguinte argumento de carácter dedutivo: a sarcofa-

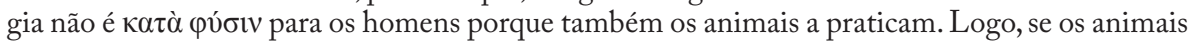

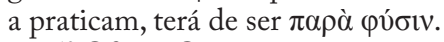

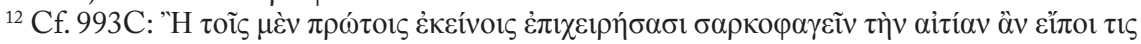

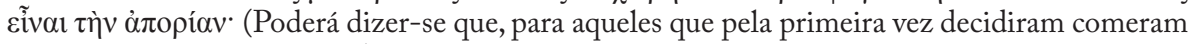
carne, o motivo foi a penúria).

${ }^{13}$ Sobre o tratado De abstinentia de Porfírio e a questão do vegetarianismo, vide D. Dombrowski 1984, P. B. Dias 2012, L. Oliveira 2013. 
por anular este princípio. Por conseguinte, Plutarco sugere uma antinomia entre civilidade e selvajaria. Por oposição ao estado selvagem, numa sociedade civilizada apenas se mata um animal quando se trata de uma situação de legítima defesa: Não vos envergonhais de misturar os nossos frutos com sangue e

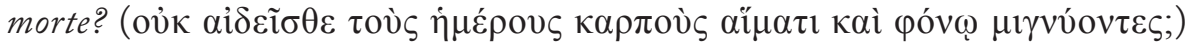
(994A). E acrescenta Plutarco para reforçar a sua ideia (994B):

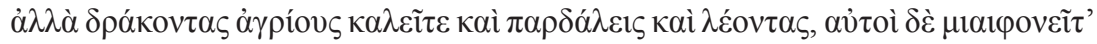

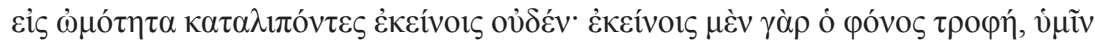

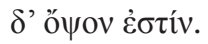

Chamais 'selvagens' às serpentes, aos leopardos e aos leões, mas quando matais não sois inferiores a eles em crueldade. De facto, para eles a morte é alimento, para vós é conduto.

Equipara, desta forma, a atitude bárbara do homem do seu tempo à dos animais selvagens, tornando-se o homem primitivo um exemplo de virtude moral. Note-se que estes estados de selvajaria e de insensibilidade do homem advêm, quando praticados com regularidade, de actividades como a caça e o sacrifício de animais, pelo facto de impedirem um sentimento de repugnância pelas feridas e pelo sangue, o que conduz o homem a experimentar o prazer de uma morte violenta (cf. 998 e 959D). Outro tema, que também é abordado no tratado De sollertia animalium ${ }^{14}$, relacionado com a selvajaria humana, é o da caça. Se para alguns é uma actividade que evidencia destreza e coragem, para outros, como Plutarco, começou por ser um acto de defesa que se transformou numa manifestação sanguinária e violenta. Depois, para evidenciar como matar animais é um acto paradoxal, argumenta Plutarco que o homem mata animais ferozes, como leões ou lobos, mas não os come. Porém, para comer, mata animais mansos e domésticos que não são uma ameaça.

Ora, na concepção plutarquiana, o homem não é semelhante aos animais carnívoros, mas tem uma physis mais próxima dos frugívoros. Comer carne constitui, desse modo, uma transgressão ${ }^{15}$, que acaba por ter reflexos no funcionamento do corpo humano que não está preparado, pela sua nature-

\footnotetext{
${ }^{14}$ No início deste tratado, em forma de diálogo, Soclaro afirma que a caça é digna de elogio (959C), mas Autobulo replica dizendo que foi por causa dela que se instalou entre os homens a insensibilidade e a crueldade. Aliás, o interlocutor de Soclaro não entende como os homens se conseguem divertir com o sofrimento dos animais. Como Pitágoras, Plutarco concorda que se possa tirar proveito dos animais sem cometer injustiça, mas condena quem age de forma contrária (964E-965B).

${ }^{15} \mathrm{Cf}$. De tuenda san. $125 \mathrm{~F}$ : por saciedade e puro prazer, o homem pode ser levado a comer de forma excessiva e não os alimentos correctos, o que pode provocar desordens e diarreias

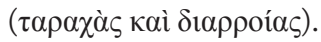


za, a digerir a carne, ao contrário dos animais ${ }^{16}$ que possuem, por exemplo, poderosas garras e dentes, para devorar a presa, ainda com vida, os seres humanos esperam que seja cadáver para modificar o seu aspecto e paladar, confeccionando-o. Não se pense, contudo, que a posição de Plutarco é radical na abstinência da carne. Se por causa do hábito o homem come carne, que o faça, mas de modo racional e motivado pelo apetite e não pela gula. $\mathrm{Ou}$ seja, repete-se novamente a tendência para uma mensagem ética que promove a moderação.

É, pois, neste quadro teórico que se recupera a doutrina vegetariana, com uma evidente influência pitagórica. Mais do que uma cuidada fundamentação médica, Plutarco desenvolve uma argumentação moral e ética, ligada a uma diaita que se rege pela simplicidade, moderação e frugalidade. Se em Porfírio ou Jâmblico, duas fontes essenciais para o conhecimento da filosofia pitagórica, a abstinência da carne está relacionada com a prática religiosa ou com a noção de harmonia entre homens e animais, seres do mesmo genos, condenando-se veementemente o sacrifício de animais, marca da cultura da Grécia Antiga, Plutarco prefere, contudo, concentrar a sua análise na refutação da concepção estóica da natureza dos animais. E, para esse objectivo, o recurso às ideias pitagóricas faz sentido. Assim sucede com duas teorias que estão interligadas: a alma é imortal e transmigra entre espécies diferentes de seres vivos. $\mathrm{Na}$ verdade, a teoria da metempsicose e da metensomatose reforça, em muito, a defesa da abstinência da carne, ainda que Plutarco não aprofunde essa teoria. Como homens e animais têm alma e podem partilhá-la, uma vez que ela é imortal, e, além disso, a vida é, em si, um valor a respeitar, para todos os seres, logo um animal também não pode ser vítima de um acto para physin (não natural). Diógenes Laércio (8.20), a este propósito, conta a história de Xenófanes que mandou parar os maus tratos a um cão porque reconhecia nos latidos a voz de um amigo.

$\mathrm{Na}$ verdade, a tradição de textos sobre a abstenção da carne, desde os pitagóricos, passando por Plutarco e Porfírio, bem como Arnau de Vilanova (c. 1238-1644), um médico espanhol, também autor de um tratado intitulado De esu carnium, ou Pierre Castellanus, de Grammont, um dos melhores eruditos da Bélgica no século XVII, autor de um tratado com igual título, demonstra a preocupação com hábitos alimentares, ainda que o teor possa oscilar entre a medicina e filosofia. No tratado hipocrático Sobre a diaita, podemos ler (2.1):

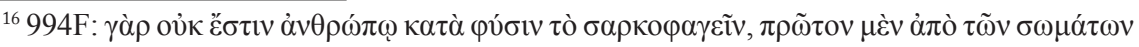
$\delta \eta \lambda$ ○̃̃ $\alpha 1 \tau \tilde{\eta} \varsigma$ $\kappa \alpha \tau \alpha \sigma \kappa \varepsilon v \tilde{\eta} \varsigma$ (De facto, o acto de comer carne não é próprio da natureza humana, como se demonstra, desde logo, pela constituição do corpo). 


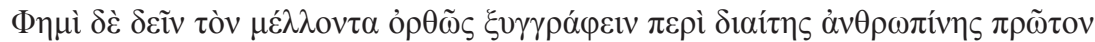

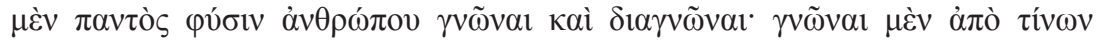

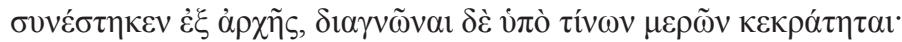

Afirmo que quem pretende compor correctamente um escrito sobre a diaita humana deve, antes de tudo, conhecer e distinguir a natureza do homem. Conhecer de que partes é constituído desde a origem e distinguir por quais é dominado.

Deste modo, para o médico hipocrático quando se fala da diaita humana, é necessário conhecer-se a natureza do homem. Por isso, propõe-se um equilíbrio entre exercício físico e alimentação. Além disso, acredita-se na importância dos factores meteorológicos, sobretudo para o estudo das doenças.

Muito embora se encontrem muitas referências à medicina e a médicos na obra de Plutarco, ela não se distingue pela sua materia medica. A posição teórica de Plutarco, como temos apresentado, é simples: compreende o princípio de utilidade e de necessidade enunciado pelos filósofos do Pórtico, mas prefere argumentar a favor da possibilidade de se viver bem, mesmo sem comer carne. Note-se que tanto Plutarco, como os Estóicos, têm uma visão antropocêntrica, mas definida de forma distinta: para os Estóicos, os animais estão ao serviço dos homens que são seres racionais, enquanto para Plutarco a abstinência da carne visa defender a natureza dos animais e dos homens, ou seja, uma noção de paridade entre seres vivos, na linha daquilo que Teofrasto, no Da Piedade (Peri eusebeias) já havia feito. Daí que Plutarco elogie a obra da natureza que, ao gerar os animais, agiu em prol da beleza e da harmonia do cosmos (cf. 994B). Por isso, a sarcofagia surge no tratado como um insulto à physis e um acto de asebeia. Vemos, assim, que o estudo do sentido e dos contextos da diaita em Plutarco, como em outros textos, remete-nos muitas vezes para hábitos e costumes comportamentais que visam o equilíbrio entre mente e corpo, alicerçado num princípio que qualquer ser reconhece e que tão bem foi sintetizado por Arífron de Sícion, num péan

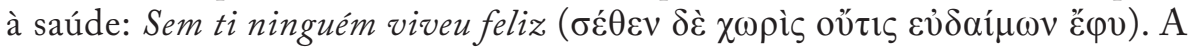
propósito da diaita, enquanto estilo de vida, conta Plutarco que Alexandre mandou embora os cozinheiros de Ada (Ásia Menor) com a justificação de que mantinha os melhores cozinheiros: para o almoço a caminhada nocturna,

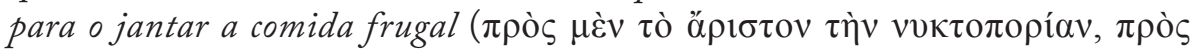

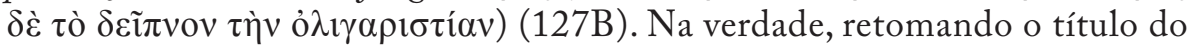
nosso trabalho, podemos afirmar que Plutarco não prescinde da medicina e muito menos da filosofia. Antes prefere uma visão integrada do ser humano, da mesma forma que não adopta uma concepção de saúde unicamente ligada à alimentação (cf. Agis-Cleom. 4.2, Tib. G. Grach. 2.4), ao exercício físico e à forma intelectual, mas sim uma visão de complementaridade.

Ainda no âmbito da concepção da diaita, insere-se a negação da sarcofagia, como estilo de vida alternativo, mais consentâneo, segundo os seus defensores, 
com a origem do homem e com a necessidade de regular a relação entre os seres vivos. Por conseguinte, a apologia de comer vegetais, em Plutarco, tem simultaneamente uma justificação médica e uma outra filosófica, na linha do pensamento pitagórico, recuperado nos séculos II e III por vários autores que sustentavam que o vegetarianismo não só contribuía para a saúde corporal, mas também para a elevação moral e ética ${ }^{17}$.

\section{Bibliografia}

Barigazzi, A. (1992), "Implicanze Morali Nella Polemica Plutarchea Sulla Psicologia degli Animali" in I. Gallo (ed.), Plutarco e le scienze, Genova, Sagep Editrice, $297-316$

Becchi, F. (1993), "Istinto e intelligenza negli scritti zoopsicologici di Plutarco", in M. Bandini \& F. G. Pericoli (Eds.), Scritti in memoria di Dino Pieraccioni, Firenze, Ist. Papirologico G. Vitelli, 59-83.

Becchi, F. (2001), "Biopsicologia e giustizia verso gli animali in Teofrasto e Plutarco", Prometheus 27: 119-135.

Becchi, F. (2002), "Lignes directrices de la doctrine zoopsychologique de Plutarque", Myrtia 17: 159-174.

Becchi, F. (2005), "Éthique et régime alimentaire dans les écrits plutarquiens de psychologie animale", in J. Boulogne (Ed.), Les grecs de l'antiquité et les animaux. Le cas remarquable de Plutarque, Lille, Université Charles-de-Gaulle - Lille 3, $145-155$.

Becchi, F. (2006), "Irrazionalitá e Razionalitá degli Animali negli Scritti di Plutarco, Ovvero:Il paradosso della superioritá razionale ed etica degli animali”, Prometheus 26: 205-225.

Boulogne, J. (1996), "Plutarque et la médecine”, ANRW 37.3, 2762-2792.

Boulogne, J. (Ed.) (2005), Les grecs de l'antiquité et les animaux. Le cas remarquable de Plutarque, Lille: Université Charles-de- Gaulle - Lille 3.

Dias, P. B. (2012), "Em defesa do vegetarianismo: o lugar de Porfírio de Tiro na fundamentação ética da abstinência da carne de animais", in C. Soares \& P. B. Dias (Coords.), Contributos para a história da alimentação na Antiguidade, Coimbra, Classica Digitalia, 81-92.

Fernandez Delgado,J.A. (2008), "On the Problematic Classification of Some Rhetorical Elements in Plutarch", in A. G. Nikolaidis (Ed.), The Unity of Plutarch's Work: "Moralia" Themes in the 'Lives', Features of the 'Lives' in the 'Moralia', Berlin, Walter de Gruyter, 23-32.

${ }^{17}$ Porfírio junta a ideia de harmonia entre o homem e os animais, propondo a abolição de sacrifícios por considerar homicídio o acto em que se mata um animal como meio para garantir alimento (De abst. 3.19). Para Porfírio, nunca se pode considerar um benefício aquilo que resulta de uma acção injusta. Por conseguinte, se o sacrifício de animais é uma acção injusta, ele não pode trazer qualquer benefício. Pelo contrário, funciona como um acto injusto, sobretudo quando homens e animais pertencem ao mesmo genos (3.25). 
Garzya, A. (1997), Percorsi e tramiti di cultura. Saggi nella civiltá letteraria tardoantica e bizantina com una giunta sulla tardizione defli studi classici. Napoli, M. D’ Auria Editore.

Inglese, L. \& Santese, G. (1999), Il cibarsi di carne. Corpus Plutarchi Moralium, Napoli, M. D’ Auria Editore.

Martin, H. (1979), "Plutarch's De Sollertia Animalium 959 B-C: The Discussion of the encomium of Hunting”, AJPh 100: 99 - 106.

Montiel Martos, J. F. (1996), "Sophrosyne o akraía: Los animales como modelo de comportamiento en los Moralia de Plutarco", in J. A. Fernandez Delgado \& F. Pordomingo Pardo (Eds.), Estudios sobre Plutarco: Aspectos Formales, Madrid, Ediciones Clásicas, 205-210.

Oliveira, L. (2013), "Justificativas para o vegetarianismo em Porfírio de Tiro", in Cultura belenistica y cristianismo primitivo: actualidade de un (des)encuentro. Actas del XIII Encuentro Internacional de Estudios Clásicos, Ed. Frías, R.U. Chile. Disponível em http://www.academia.edu/11795830/Justificativas_para_o_Vegetarianismo_ em_Porf\%C3\%ADrio_de_Tiro (30 de Junho de 2015).

Ramón Palerm, V.(2001:), "Misticismo, filosofia y retórica en De esu carnium”, in A.Pérez Jiménez \& F. Casadesús (Eds.), Estudios sobre Plutarco. Misticismo y Religiones Mistéricas en la Obra de Plutarco (Actas del VII Simposio Español sobre Plutarco, Palma de Mallorca, 2-4 nov. 2000), Ediciones Clásicas \& Charta Antiqua, Madrid \& Málaga, 211-220.

Tsekourakis, D. (1987), "Pythagoreanism or Platonism and Ancient Medicine? The Reasons for Vegetarianism in Plutarch's 'Moralia”, ANRW2.36.1: 366-393.

Van der Stockt, L. (Ed.) (2000), Rhetorical Theory and Praxis in Plutarch, Acta of the IV International Congress of the International Plutarch Society, Leuven, July 3-6, 1996. Louvain \& Namur: Éditions Peeter \& Société des Études Classiques.

Van Hoof, L. (2011), "Plutarch's 'Diet-Ethics'. Precepts of Healthcare between Diet and Ethics", in G. Roskam \& L. Van der Stockt, Virtues for the People. Aspects of Plutarchan Ethics, Leuven, Leuven University Press, 109-129.

Vegetti, M. (1994), "L'immagine del medico e lo statuto epistemológico della medicina in Galeno”, $A N R W 37.2: 1672-1717$. 